\title{
The Ethics of Engagement in an Age of Austerity: A Paradox Perspective
}

\author{
Helen Francis ${ }^{1}$ (I) $\cdot$ Anne Keegan ${ }^{2}$
}

Received: 4 September 2017 / Accepted: 12 July 2018 / Published online: 13 August 2018

(c) The Author(s) 2018

\begin{abstract}
Our contribution in this paper is to highlight the ethical implications of workforce engagement strategies in an age of austerity. Hard or instrumentalist approaches to workforce engagement create the potential for situations where engaged employees are expected to work ever longer and harder with negative outcomes for their well-being. Our study explores these issues in an investigation of the enactment of an engagement strategy within a UK Health charity, where managers and workers face paradoxical demands to raise service quality and cut costs. We integrate insights from engagement, paradox, and ethic of care literatures, to explore these paradoxical demands-illustrating ways in which engagement experiences become infused with tensions when the workforce faces competing requirements to do 'more with less' resources. We argue that those targeted by these paradoxical engagement strategies need to be supported and cared for, embedded in an ethic of care that provides explicit workplace resources for helping workers and managers cope with and work through corresponding tensions. Our study points to the critical importance of support from senior and frontline managers for open communications and dialogue practices.
\end{abstract}

Keywords Engagement $\cdot$ Ethic of care $\cdot$ Paradox

\section{Introduction}

Our contribution in this paper is to highlight the ethical implications of workforce engagement strategies in an age of austerity. Paradoxical engagement strategies cause tensions, and those targeted by these engagement strategies need to be supported and cared for. Empirical evidence points to a growing instrumentalism or 'hard' approach to engagement interventions (Arrowsmith and Parker 2013), which creates the potential for situations where engaged employees are expected to work ever longer and harder with negative

Helen Francis and Anne Keegan have contributed equally to the paper and are listed alphabetically.

Helen Francis

h.francis@napier.ac.uk

Anne Keegan

anne.keegan@ucd.ie

1 The Business School, Edinburgh Napier University, Edinburgh, Scotland, UK

2 HRM and Employment Relations Group, College of Business, University College Dublin, Dublin, Ireland outcomes for their well-being (Jenkins and Delbridge 2013; Robertson and Cooper 2010). Our study explores these issues in an investigation of the enactment of an engagement strategy at a UK Health charity (pseudonym of HealthOrg); infused with tensions arising from paradoxical demands to raise service quality and cut costs. We highlight the importance of an ethic of care (Gilligan 1995) in shaping the explicit resourcing of structures and practices that enable workers and managers to cope with corresponding tensions.

Support from senior and frontline managers for the construction (and maintenance) of open communication and dialogue practices are shown to be critically important to building work environments that enable 'engaging experiences' for our research participants (Shuck et al. 2011). It was important for them to have opportunities to talk about and engage with tensions at play-providing psychological safety to express doubts and anxieties with peers and managers, and to agree on ways to manage these. These discursive practices are shown to positively frame experiences of engagement, consistent with earlier research (Kahn 2010). In contrast, we also observe in our data, the negative implications for workers and managers confronted with recasting of priorities, when they do not feel their managers are 
listening or providing opportunities for dialogue in order to help them work through the consequences of paradoxical demands. 'Disengaging experiences' (Shuck et al. 2011, p. 310) of this kind are marked by expressions of frustration, anxiety and hopelessness; where participants feel that there is little or no space to voice doubt or criticism, or to develop the means of working towards solutions.

Our paper is structured into four sections. In section one, we present the theoretical background to our study, leading to a set of research questions. In section two, we explain the context of our study and methods. In section three, we detail the results of our investigation, followed by two sections that provide a discussion of the theoretical and practical significance of our findings (including limitations). In the final section, we conclude the paper and provide suggestions for future research.

\section{Theoretical Background}

We combine theoretical insights from engagement theory, paradox theory, and an 'ethic of care', to make a novel contribution to engagement research. Each of the strands of our theoretical basis for the study is now presented.

\section{Engagement Theory}

The seminal work on employee engagement is widely recognized as that of Kahn (1990), who's holistic concept of 'personal engagement' builds on Goffman (1961). Engagement is described as a motivational process, with fluctuations in the extent to which employees express their 'personal selves' during particular 'moments' of role performances; described as the 'simultaneous employment and expression of a person's "preferred self" in task behaviors that promote connections to work and to others' (Kahn 1990, p. 700). Moments of engagement are characterized by the simultaneous investment of physical, emotional and intellectual energies, shaped by three psychological conditions: the extent to which employees feel a sense of meaningfulness, psychological safety and availability of resources to engage in work-related tasks.

Conversely, Kahn defines personal disengagement as the 'simultaneous withdrawal and defense of a person's preferred self in behaviors that promote a lack of connections, physical, cognitive, and emotional absence' (ibid p. 701). Engagement is thus not simply a personal accomplishment or failure, but a precarious accomplishment linked with the social context. Kahn explains that people experience meaningfulness when they feel worthwhile, useful and valuable, derived from high-quality relationships which heighten the individual's sense of belonging, purpose and sense of return in bringing their "whole selves" to their work. Psychological safety is feeling able to show and employ one's self without fear of negative consequences; this condition is treated as a function of trusting and caring relationships. Psychological availability is a sense that the individual has the physical, emotional, and intellectual resources to engage at particular moments in time and is affected (positively and negatively) by the nature of the relationships organizational members create and maintain (Kahn 1990, 1993, 2010).

Theorists have subsequently built on Kahn's work to devise measures of engagement which vary in terms of incorporating the broader social, political and ethical context (Bailey et al. 2017; Purcell 2014). A dominant, and alternate perspective on engagement that emerged from Kahn's original work, developed by the Utrecht Group, delineates engagement much more narrowly, as an enduring (measurable) psychological state of mind (Bailey et al. 2017). Underpinned by a unitary bias, focus is given to defining and measuring the individual's psychological relationship to work, described as 'work engagement' and conceived as 'a positive, fulfilling, work-related state of mind characterized by 'vigour', 'dedication', and 'absorption' (Schaufeli 2014, p. 19). Kahn argues that this current focus on work engagement emphasizes self-employment (in terms of intensity of effort and dedication) at the expense of self-expression, and presents a renewed focus on his original term of personal engagement, in order to raise the significance of individual agency, psychological well-being and the relational contexts that shape this (Kahn 2010; Kahn and Heapy 2014, p. 93).

Kahn's emphasis on relational practice echoes current scholarship on dialogue within organizations. Dialogue is commonly treated as an ideal type of conversation (Stewart and Zediker 2000)—something to be striven towards, and differentiated from argument and debate-viewed as a particular quality of ethical relating, with a focus on sustained collective inquiry (Reitz 2015; Isaacs 1999). Others adopt a more descriptive view of dialogue, defined as a more pervasive meaning-making process (Stewart and Zediker 2000; Reitz 2015, p. 21), with emphasis placed on a quality of relating that can include a variety of conversational types, as long as they are underpinned by an egalitarian ethos, and the recognition of different positions and values (Barge and Little 2002; Escobar 2009). Drawing on the latter viewpoint in this paper, we treat dialogue as a form of relational conversational practice, that promotes an openness to change, embraces uncertainty and provides opportunities to work with tensions creatively (Lewis and Smith 2014; Reitz 2015).

Notwithstanding the growing 'psychologization' of engagement (Goddard 2014; Harley 2015; Purcell 2014), efforts are being made to broaden the engagement lens in ways that consider the wider social context or 'climate' of work engagement (Bailey et al. 2017; Bakker et al. 2011, p. 12; Freeney and Fellenz 2013). Social exchange theory 
has been widely applied to examine mutual exchange relationships within the organization and their shaping influence on engagement. Various measures of engagement have been developed that have drawn linkages with commitmentseeking HR practices (Albrecht et al. 2015), and perceived organization/manager support, voice, and trust (Rees et al. 2013; Fletcher and Robinson 2014). Consistent with Kahn's emphasis on a supportive work climate, perceived organizational support-the extent to which the organization they work for values their contributions and cares for their wellbeing-has been identified as a particularly significant predictor of engagement with work, and also with the organization (Saks 2006; Crawford et al. 2014).

Practitioner oriented models treat engagement as an instrumental workforce strategy that focuses on the employees' psychological relationships with their organization rather than work tasks, including behavioural outcomes arising from this, such as discretionary effort (Truss at al. 2013). These models play down the impact of tensions arising from contradictory interests or identifications (Jenkins and Delbridge 2013, p. 2672) faced by managers and employees when confronting paradoxical demands arising from the work situation (Thompson 2011). Critical (Jenkins and Delbridge 2013) perspectives on engagement challenge these narrow assumptions and the underlying 'resource' metaphor framing engagement specifically, and human resource management generally (Keegan and Francis 2010; Francis et al. 2014).

People are often not aware of using metaphors because they take them for granted, and begin to reify them (Akin and Palmer 2000; Oswick et al. 2004), exemplified in the literal usage of the human resource metaphor amongst academics and practitioners to denote employees as passive commodities or assets to be utilized (Legge 1999) rather than as active agents. The resource metaphor in HRM potentially de-humanizes workers and managers (Inkson 2008; Legge 1995) and underpins static de-contextualized models of engagement which frame employees as predictably reacting to engagement strategies, rather than shaping their work environment (Purcell 2014). Thus, while Kahn conceptualizes engagement as a precarious (tension-filled) accomplishment, the question of how engagement plays out in a social context when goals of engagement are paradoxical, is currently not well researched. Paradox theory can shed some light on this.

\section{Paradoxical Tensions and Discourses of Engagement}

There is a growing body of research offering insights into the nature and management of tensions facing individuals and organizations (Lewis and Smith 2014), also in terms of HRM (Keegan et al. 2017; Aust et al. 2015). Paradox theory focuses on tensions between "interrelated elements that seem consistent in isolation but incompatible or contradictory in conjunction such as differentiation and integration or exploitation and exploration" (Andriopoulos and Lewis 2009; Lewis and Smith 2014; Jarzabkowski and Lê 2017, p. 434). The tensions accompanying a paradox are experienced as "[s]tress, anxiety, discomfort, or tightness in making choices, responding to, and moving forward in organizational situations" (Putnam et al. 2016, p. 69) because a clear choice cannot be made between the interrelated elements offered as part of an organizational or engagement strategy. Different types of paradoxes are identified in the extant literature. Following the seminal work of Lewis (2000) and Smith and Lewis (2011), paradoxes can be associated with performing (goal setting) and belonging (identity/interpersonal relationships). Performing paradoxes creation tensions due to the pursuit of "multiple and competing goals" (Smith and Lewis 2011, p. 383). Belonging paradoxes emerge as actors identify themselves with contradictory and interrelated "values, roles and memberships" (Smith and Lewis 2011, p. 383).

The management of elements that are contradictory but interrelated-for example being both family and business oriented in family-owned businesses, or being public service and budget oriented in cash-pressed public services likes schools and hospitals-can cause stress for employees and managers (Luscher et al. 2006). Putnam et al. (2016) explain that paradoxes are embedded within larger structures and social systems such as opposing demands written into a company strategy to achieve both standardization and personalization of service provision (Heracleous and Wirtz 2014). Paradoxical tensions are articulated in the form of mixed managerial messages and inconsistent organizational strategies reinforced by competing organizational discourses (Lewis 2000). The power dynamics shaping these processes can mean paradoxes are openly highlighted and discussions of tensions are openly facilitated (e.g. Luscher and Lewis 2008), or paradoxes are glossed over, kept silent and tensions suppressed (Putnam et al. 2016).

The impact of open discussion on tensions, when strategies are 'recast' in ways that make contradictory elements simultaneously important, may lead to different responses from individual actors. Studies show how actors' discursive responses to paradox can be defensive (avoidance-based) or more proactive (accepting, embracing) in their approach. This suggests that the existence of paradoxical phenomena is not simply a 'given' but becomes salient in and through discourses and social relations emerging within the organization and beyond (Smith and Lewis 2011), through dialogue and everyday interactions (Putnam et al. 2016).

While conversational practices may enable stakeholders to build fresh insights about paradox, their potential to create a 'new reality' may not succeed however, unless the practice is relationally focused with 'dialogic overtones' (Barge 
and Little 2002, pp. 80-81), enabling psychological safety for doubts to be expressed and engagement in a process of 'resourceful sensemaking' and collaborative problem solving (Putnam et al. 2016, p. 2011). Making people aware of elements in tension, without providing space for exploration and discussion of working through problems, may thus reduce rather than enhance engagement with such paradoxical strategies. Empirical work by Luscher and Lewis (2008) suggests that this is a process that takes time. It requires consistent efforts to work through resistance and provide continuous, ongoing support to managers and employees.

Following from this, we take the view that discourses of engagement can act as 'discursive resources' as well as 'rules' (Watson 1994) that people draw upon within moments of being engaged in the performance of work tasks. Following Fairclough $(2003,2005)$ we treat discourse as text (written, spoken, visual), an instance of discursive practice and an instance of social practice. Organizations have their own distinctive 'orders of discourse' (Fairclough 2003) which vie with each other for dominance at different levels of decision-making (Grant et al. 2004, p. 15). Our study focuses on the human experience of engagement, notably the tensions individuals describe facing in their discursive enactment of work tasks and engagement with their employing organization, and the discourses they draw on in these processes.

\section{Encompassing an Ethic of Care}

The final strand of the theoretical basis for our paper is an 'ethic of care', which positions moral reasoning around notions of connectedness and caring for people (Gilligan 1995). This enables us to shed light upon the interrelated challenges of engagement, ethics, and resource pressures in contemporary organizations, and how this shapes people's experiences of the paradoxical nature of engagement. Consistent with a Kantian approach, an ethic of care treats the means, or the process by which people are managed as most important, in contrast with consequentialist approaches where the end justifies the means (Parkes and Harris 2008). Specifically, this lens adds an 'imperative of care for self and others' in the context of relationships, with less importance given to individual rights or obligations (Machold et al. 2008). An ethic of care is understood as a form of social practice, with emphasis placed upon strengthening relationships, embracing a sensitivity and responsiveness to the feelings of others, while seeking to fulfill (sometimes conflicting) responsibilities to different people (Bauman 2011; Simola 2003), much of which revolves around dialogue (ie talking, listening, sharing stories, Liedtka 1996; Lawrence and Maitlis 2012).

Although not based explicitly on an ethic of care, Kahn's $(1993,2005)$ empirical investigations of relationships within caregiving organizations encompasses its distinctive elements (Lawrence and Maitlis 2012, p. 644), also evident in his re-examination of the relational context of engagement (Kahn and Heapy 2014). Leaders play a pivotal role as facilitators in exploring underlying tensions, issues and events, enabled by 'cultures of inquiry' which support the prioritization of care-giving, high-quality connections and meaningful dialogue (Kahn 2005, p. 185). Kahn provides examples of reflective spaces (ie. supervisory meetings and agency-wide forums), structured to enable discussion and working through tensions at play, such as the autonomy versus control tension experienced by care workers. Reflective practices of this kind are dialogic (Stewart and Zediker 2000), similar to the kind of 'narrative practices' embedded in enduring relationships found in work teams and individual worker-line manager relationships (Lawrence and Maitlis 2012). Importantly, they are underpinned by constructionist principles that enable people to share, understand and respond to the struggles and uncertainty faced by others; contextualizing them, and working to foster the growth and development of the cared for (ibid p. 647).

Environments that sustain dialogue and associated relational features consistent with an ethic of care are becoming increasingly relevant as organizations experience growing pressure to deliver on the broad ethics and responsibility agenda (Parkes 2012; Groysberg and Slind 2012; Jacobs and Keegan 2016), while seeking to advance workforce engagement and cut costs and do more with less resources. As organizations begin to rely on the interdependency of fewer core staff to maintain the same or better levels of performance, trust, reciprocity, an expression of caring relationships and cultures of inquiry are likely to provide critical pathways to genuine reconciliation of (competing) stakeholder needs and interests (Greenwood 2002; Machold et al. 2008; Francis et al. 2014). It follows that where the performance of tasks are in tension, an engagement deficit on the part of workers may not indicate an unwillingness of workers to engage, but reflect relational organizational contexts that suppress, rather than promote acceptance and understanding of contradictions and tensions in local and broader socio-economic conditions (Greenwood 2002; Greenwood and Freeman 2011; Kahn 2005; Spicer et al. 2009; Watson 2010).

To conclude, on drawing links between emergent literatures on paradox theory, engagement, and an ethic of care, our study provides a unique and necessary lens that highlights ethical implications of engagement strategies when people are faced with paradoxical demands. In doing so, we provide fresh insights into people's experiences of being and staying engaged in paradoxical situations. Little academic research has investigated the actual experience of being engaged in its various forms (eg. directed towards work tasks, ones employing organization, colleagues, and teams: 
Saks 2006; Schaufeli and Salanova 2011); including how workers react to workforce engagement strategies (Shuck et al. 2011; Bailey et al. 2017) especially those that contain tensions between contradictory demands in the face of an increasing scarcity of resources (Greenwood 2002, 2007; Purcell 2014). Paradoxically, an 'ethic of care' appears to be somewhat neglected amidst the ongoing repositioning of (technology-enabled) HR functions, in an era when worker engagement is of critical importance (Francis et al. 2014, p. 1334).

\section{Research Questions}

We combine theoretical insights from engagement theory, paradox theory and an ethic of care, to make a novel contribution to engagement research by studying a workforce engagement strategy in a HealthCare Organization (HealthOrg). Our study addresses three research questions:

- What are the paradoxes of engagement for workers and managers in HealthOrg?

- How are paradoxes of engagement linked to the interplay of paradoxes and discourses at organizational and sector levels?

- How do personnel discursively frame and respond to engagement paradoxes, and what are the ethical implications for the active management of workforce engagement?

\section{Study and Methods}

The study we present here is part of a wider investigation undertaken over a period of 18 months (2013-2015), of the development of a business-oriented engagement strategy at HealthOrg, arising in response to contradictory pressures facing the organization: the need to reduce costs in the face of government austerity measures, and at the same time to maintain customer service levels consistent with the sectors' core values.

The charity employed 700 staff at the time of the research, made up of an executive team (11 members); senior managers (14); middle managers (80), and non-managers (595). Rapid growth in HealthOrg's workforce by $40 \%$ between 2001 and 2010 was stimulated by the contracting out of public social services to this particular sector. The rationale was that services delivered to client groups would gain in quality because of high levels of mutuality in the employment relationship and a commitment to social causes that characterize employment patterns in the voluntary sector (Cunningham 2010). These shared attitudes and values are often described as the 'voluntary service ethos' (VSE), defined as 'a commitment to a cause and feeling valued and supported in contributing towards this' (Cunningham 2010, p. 701).

The voluntary service and public sector management worlds are characterized by dominant discourses which are fundamentally different in orientation, and thus the source of potentially paradoxical tensions. The dominant discourse of the voluntary sector, which we label here as the VS discourse, encapsulates an expressed commitment to a social cause and social justice, such as mental health care for all members of society (Potter et.al. 2012). As the partnership between public and voluntary sectors grows, this indigenous discourse has become interwoven with another competing dominant discourse surrounding public sector management. Embodied in New Public Management (NPM) inspired reforms from the 1980s (Rees 2014) we label this the NPM discourse. It is signified by a 'contract culture', and agenda of cost control and maximization of efficiency (Chaney and Wincott 2014).

\section{Qualitative Data Collection}

Management realized that a quantitative survey gathering insights into numerical aspects of state engagement (gathered as part of another comparative study), might not tap into tensions of being engaged in a climate of 'austerity'. For this reason, they agreed to include three questions with FTRs (full text responses) developed by the researchers to qualitatively explore peoples' experiences of workplace tensions, how they pursue meaningfulness in their work, and line manager support for working through problems:

(1) What is the best thing about working for HealthOrg?

(2) Describe the biggest tension that you currently face in the workplace

(3) Describe how you have worked with your line manager to find the best way of getting something done.

Open-ended questions eliciting FTRs are well suited to exploratory research into respondents' experiences of a topic that cannot be adequately explored through closed survey questions. In comparison to interviews, this method also offers greater anonymity to respondents and may elicit more honest responses about sensitive subjects (Jackson and Trochim 2002). As well as the qualitative data derived from FTRs we also rely on notes from several informal meetings and two formal interviews held with the HR director and HR business partner throughout the study, alongside relevant company documentation, including HealthOrg's corporate strategy, engagement strategy, corporate bulletins, and management briefing notes, gathered pre and post the launch of the engagement survey. All data were uploaded to Nvivo software which provides advanced data-handling and manipulation features for computer-based discourse analysis 
(Blismas and Dainty 2003). FTRs were auto coded alongside the original survey dataset, allowing us to run automated 'queries' that enabled us to compare and contrast FTRs across three different job levels (worker, manager, senior manager). Of the 306 survey participants (approximately $46 \%$ of the 750 employed at HealthOrg), over half responded to the three questions as shown in Table 1.

We use techniques from Critical Discourse Analysis (Fairclough 2005) to analyse FTRs, working towards a coding framework. This included a-priori codes (which reflected our orienting theoretical perspective and research questions), and emergent codes based on the texts themselves (King 2004). Coding and analysis involved three phases. First, we drew up a preliminary analysis of themes based on the authors' reading and familiarization of all FTRs and broader data such as HR interviews and documentation. This process was followed by allocating all FTRs to an agreed preliminary coding framework (created as Nvivo nodes), made up of broad themes (e.g. types of tensions; responses to paradoxes; discursive framing of responses; meaningfulness of work/ particular tasks), and successively narrower, more specific sub-themes (e.g. 'Flailing', 'Muddling through' and 'Generating' responses). New codes were created and/or refined during this process, as additional sub-themes emerged and were discussed and agreed between the authors. Inter-rater reliability checking was not possible given the emergent nature of this coding process, and coding decisions therefore required explicit reflexivity in terms of theoretical aims and use of sensitizing concepts (Janssens and Steyaert 2009).

In phase three of our analysis, we generated matrix coded displays in Nvivo enabling us to check for discursive patterns across the data set as a whole. Multiple codes were attached to the same block of texts, reflecting the interwoven nature of paradoxes and organizational discourses (Palmer and Dunford 2002). We took care to ensure the analysis of these was not confined within the boundaries defined by Nvivo. In our final phase of analysis, we therefore drew upon hard copies of Nvivo reports to undertake a close reading of these texts and make a constant effort to compare our interpretations of these with other information gathered, providing us with a 'triangulation strategy' for the study (Vaara et al. 2010). In doing so, we drew on Fairclough's concepts of intertextuality (how an individual text draws on elements of other texts) and 'hegemonic struggle', as we explored ways in which sector level discourses are mobilized, contested and re-ordered by actors in their everyday interactions, shaped by an underlying dimension of power. Table 2 identifies key terms and expressions evidenced at three levels of analysis (individual, organizational, sector). We present illustrative texts that exemplify respondents' experiences of engagement (and disengagement), embodied in various encounters of working life, and the paradoxical nature of these engagement experiences.

\section{Results}

\section{Core Organizational Paradox}

Since 2013, HealthOrg has become increasingly reliant on local government contracts, consistent with sector trends (Rees 2014). These typically require more extensive monitoring than other funding types, alongside a necessity to do 'more with less resources' in the face of growing public sector budget restrictions (Cunningham and Nickson 2011). This forms a core organizational paradox at HealthOrg, of service excellence versus service efficiency, which is becoming increasingly salient for staff through talk of 'losing contracts to competitors' (HR Business Partner) and a wider political discourse of austerity. HealthOrg strives to maintain a 'quality service' that can be differentiated from private agencies which have crowded into the (government funded) mental health care service sector in recent years. As competitive pressures increase, these agencies provide services which are perceived by HealthOrg staff as not the same quality of service, leading to a potential 'erosion of charitable values' (Rees 2014, p. 56). In HealthOrg, the tension arising from these paradoxical elements is felt by individuals in terms of the challenge it presents to the importance of meaningful work. Meaningful work is typically couched as having a chance to make a 'real difference' in people's lives, illustrated in the following FTRs about the 'best thing about working at HealthOrg':

Table 1 Free text responses rates across all job levels

\begin{tabular}{|c|c|c|c|c|}
\hline & Non manager & Manager & Senior manager & Total \\
\hline Number of responses & 196 & 67 & 18 & 281 \\
\hline Q1 What is the best thing about working for HealthoOrg? & $\begin{array}{l}135 \\
68.8 \%\end{array}$ & $\begin{array}{l}45 \\
67.1 \%\end{array}$ & $\begin{array}{l}15 \\
83.8 \%\end{array}$ & $\begin{array}{l}195 \\
69.6 \%\end{array}$ \\
\hline Q2 Describe the biggest tension that you currently face in the workplace? & $\begin{array}{l}102 \\
52 \%\end{array}$ & $\begin{array}{l}38 \\
56.7 \%\end{array}$ & $\begin{array}{l}8 \\
44.4 \%\end{array}$ & $\begin{array}{l}148 \\
52.6 \%\end{array}$ \\
\hline $\begin{array}{l}\text { Q3 Describe how you have worked with your line manager to find the best } \\
\text { way of getting something done? }\end{array}$ & $\begin{array}{l}104 \\
53 \%\end{array}$ & $\begin{array}{l}40 \\
59.7 \%\end{array}$ & $\begin{array}{l}14 \\
77.7 \%\end{array}$ & $\begin{array}{l}158 \\
56.22 \%\end{array}$ \\
\hline
\end{tabular}




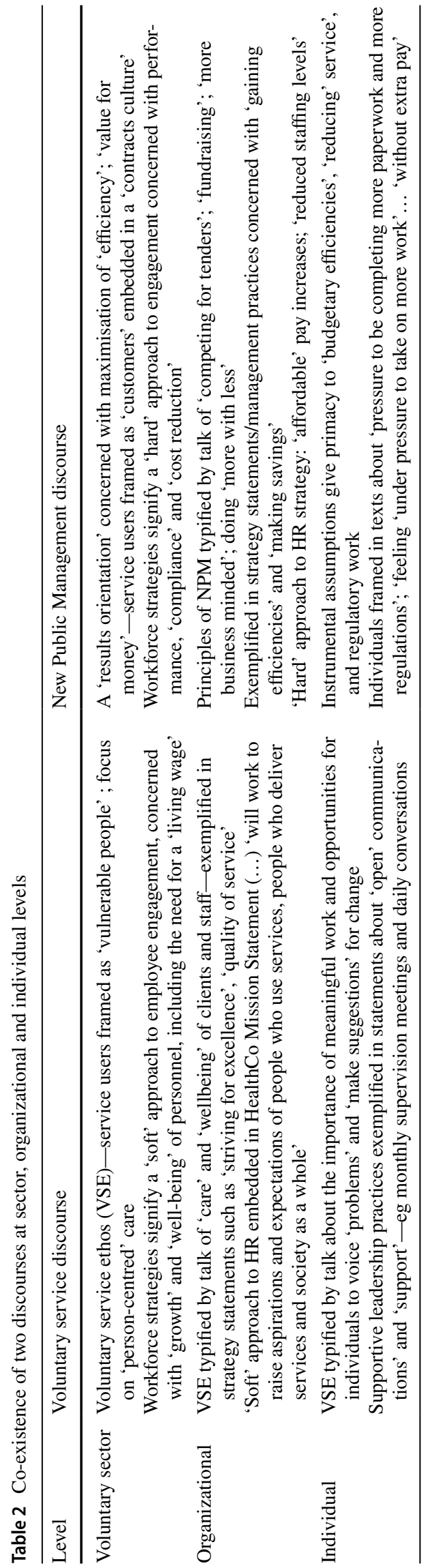

Working with people and seeing how we can make a difference in someone's life. There is nothing more rewarding than supporting someone to have a better quality of life.

(Worker)

Very simply put, it is the very core of our business: reaching out to communities to assist vulnerable adults to live a fulfilling life despite mental health issues and addictions (Line manager).

Textual analysis shows how the NPM discourse became amplified in strategies for change, as HealthOrg sought to continue to provide 'excellent service levels' and simultaneously to generate efficiencies. These opposing demands are discursively framed by the senior team within communications to staff, as complementary and interwoven, indicative of a 'both/and' perspective on paradox (Lewis 2000). This is reflected also in the intertextuality of concepts and expressions used to provide a measure of legitimacy to management plans articulated in a Corporate Strategy Bulletin to all staff. Framed by business and efficiency-oriented concepts indicative of the NPM discourse, the Bulletin refers to a corporate savings plan aimed at achieving ' $3 \%$ saving of total budget', and a need for HealthOrg 'to adapt and be able to respond to an increasingly competitive market place and achieve significant efficiencies'. This statement is followed by reference to the launch of a workforce engagement strategy (labelled as the 'Value and Recognition Strategy') - framed rhetorically by the need for 'HealthOrg be flexible and responsive to the external environment' and reference to a recent agreement on a pay award with the Trade Union that was 'aligned to meet our business model and our strategic direction'.

Statements about external drivers noted in these communications are juxtaposed with talk of service ideals embedded in the more relational-oriented VS discourse, framing a declaration that.

(...) "The Value and Recognition Strategy will help HealthOrg strive for organizational excellence and be seen as a leading employer which values and recognizes its workforce". In a later bulletin for managers, the importance of maintaining service standards is re-emphasized, and connected to building staff engagement with new business values:

You may be wondering what we mean by Value and Recognition - it's about the relationship between HealthOrg employees and HealthOrg as the employer. Value and Recognition covers a number of things: it covers how we value staff and recognize their contribution appropriately; terms and conditions; and ensuring we have a flexible workforce (...) All of this is to enable us to have a positive impact on the people we support; the partners we work with and to promote and 
protect HealthOrg to grow and be successful' (Briefing Note to Managers).

We now discuss our findings on two main paradoxes at the individual level, seeming to flow from this core organizational paradox of cost control and customer service, illustrating how people are constructing struggles they and others face, and ways in which the relational context appears to constrict or expand opportunities for them to reflect on, and work with, paradoxical tensions.

\section{Paradoxes of Engagement}

Our textual analysis of FTRs points to paradoxes of engagement which we coded as paradoxes of performing-engaging with what? and of belonging — engaging with whom?

Performance paradoxes are linked to the need for HealthOrg to focus on both social care and paperwork/audit regulation; and service excellence as well as service efficiency. These contradictory elements are paradoxical because the possibilities to keep doing meaningful work is seen to depend on 'getting contracts', and contracts depend on being able to carry out procedural and compliance tasks that are-at the same time-perceived as driving out space for meaningful work with end users (HR Director). Secondly, tension between service excellence versus service efficiency becomes increasingly salient to organizational members amidst the presence of growing budget cuts by local authorities marked by reduced contact hours for service users.

As the organization becomes more commercially focused-paradoxes of engagement also emerge at the belonging level. HR respondents explained that the recent reorientation within HealthOrg to more commercial activities is seen part of a strategy to reduce reliance on government funding and with it also a reduction in competition with private agencies. This however requires investment in personnel and resources that are not oriented directly to service work and service excellence, signalled by the mobilizing of a more commercial-oriented NPM discourse by some senior staff. As this discourse interpenetrates the traditional voluntary service ethos, paradoxes of belonging emerge for workers and managers, manifested in tensions between commercial identity versus service identity.

The quality of service to clients is absolutely key for us all and a fundamental reason why people work in this type of organization ... this constant talk about doing more with less ... how are we supposed to become more business-minded without losing our values as an organization? (HR Director)

In what follows we draw on sample narratives to illustrate how workers and managers discursively frame and respond to paradoxes of engagement, which we label flailing, muddling through, and generating. These are characterized by varying opportunities for participants to engage in (dialogic) conversations about tensions and performance of contradictory tasks and roles. Consistent with extant research, the emergence of paradoxical tensions appeared to open up or close off worker participation in decision-making, depending on whether line managers (and their seniors) privileged monologue or dialogic modes of communication about tensions at play (Putnam et al. 2016, p. 121; Kahn 2005). In terms of the latter, immediate line managers appeared to play a pivotal role as facilitators in promoting relational practices (ie. feedback sessions) that enabled meaningful dialogue around the exploration of tensions, issues and events, and ways of managing these.

\section{'Flailing' Responses and Paradoxes of Performing}

Flailing responses discursively close off possibilities respondents see for engaging in both elements, or poles of the paradox, and are characterized in the texts below, by an impoverished relational context and 'ethic of care' about how to fulfill conflicting responsibilities (Bauman 2011). In our first illustrative text, we interpret the response as a defensive reaction to paradoxes of performing. By choosing a selection response (Lewis 2000)-i.e. selecting one pole (care work) and minimizing the other (paperwork), client work is 'always prioritized' over paperwork. This 'either/ or' discursive framing draws on the VS discourse to justify minimizing or ignoring paperwork duties and elevating 'care' duties.

At times I feel I am working whilst some others chose to read over paperwork and I am aware that this is vital at times to catch up on paper work. However, I feel it's important to do the work required with service users and that they should always come before paperwork no matter how long it takes to get this up to date (Worker).

Defensive responses offer short term relief in coping with tensions, but they often exacerbate stress in the longer term, as they do not provide a new way to work with or understand the paradox (Putnam et al. 2016) in contexts where, because of scarce resources or other issues, the freedom to ignore one element is non-existent, as illustrated in the following text:

Low level of staffing means that I am alone working majority of the time and having an increased paperwork load - which can affect the quality of support offered to service users, as I do not have enough time to keep paperwork up to date and effectively support service users. It can also lead to me frequently staying later when my shift ends to ensure work is completed, 
and in turn this and the above can affect my own stress levels and mental health (Worker).

We interpret this individual as choosing a separation strategy (Putnam et al. 2016) segmenting the two poles in order to undertake different duties at different times. Dominance of the NPM discourse is evident in this text, whereby objectives pertaining to maintaining staffing levels and service standards are suppressed (Jarzabkowski et al. 2013) by more senior managers in favour of other objectives related to cutting costs. Perceptions of lack of voice and poor dialogue with senior/head office personnel about tensions associated with maintaining frontline services is exemplified further in the next text, indicating a sense of powerlessness as things reach a 'tipping point':

Poor support from further up the organization. An expectation that you can just work with anything thrown at you. More hours, less salary, less staff, stand still budgets. It feels like this service now has no slack at all and frequently reaches tipping point. There is no cover, no budget for cover, if people are off sick. Trying to develop the service is made impossible by the way finance is managed and use of things like the internet. Issues are either shelved and forgotten about or left until the last minute (Manager).

In this context, the manager appears to feel that workers' demonstration of engagement in the form of discretionary work is assumed, or expected amongst senior managers, in the face of external pressures for greater efficiencies: expectations that are also evident amongst narratives of frontline workers:

I feel that HealthOrg are continuously expecting more from Staff over and above their day to day role. Therefore this means you end up with more work than time in a day to complete it. Also this increase in additional work is not recognised in the payscale (Worker)

A reducing managerial 'presence' in HealthOrg services is also implicated in concerns about a reduced scope to deliver the 'quality' of support to service users that care workers are used to providing (especially workers). In the words of one senior manager:

(...) in order for the service to remain within the budget team leaders are expected to deliver up to 16 hours from their management time and this has an impact on their ability to actually manage the service. This impacts on their ability to effectively complete management tasks within deadlines and to develop personally. They need to have more of a presence in services. (Senior Manager)
'Flailing' Responses and Paradoxes of Belonging

The narratives below point to a sense of hopelessness in the face of a paradox of belonging that accompanies paradoxes of performing. As noted earlier, paradoxes of belonging, following the seminal work of Lewis (2000) and Smith and Lewis (2011), are associated with challenges to identity/ interpersonal relationships because of the pursuit of contradictory and interrelated "values, roles and memberships" (Smith and Lewis 2011, p. 383). Our data point to engagement tensions arising from demands to perform job roles characterized by clashes in personal values and a sense of identity that comes with having to perform duties that fall short of the kind of care work professional care workers pride themselves in doing - such as spending 'quality time' with clients, listening to their needs and looking after their overall well-being - while demands for task performance are becoming more heavily weighted towards basic tasks such as cleaning and general maintenance of the home. This shift in balance of tasks is rooted in the move towards commercially focussed business values, and imposition of funding cuts/ new contractual arrangements with government agencies, consistent with broader sector trends (Cunningham 2010).

Illustrations of how workers encountered this paradox of belonging, reflect 'disengaging experiences' (Shuck et al. 2011) that have the potential for individuals to disengage (or withdraw) from their job roles (cognitively, emotionally and physically), as their work contributes to them feeling estranged from their own values (Smith and Lewis 2011; Wollard 2011).

I feel that as an employee my values are being compromised as I do not feel we are given time to spend with clients as their hours are not being met as we have staff shortages (Worker)

Not being able to support the service users with their mental health issues and life direction. Time is taken up by cooking, cleaning, medicating, providing personal care and health \& safety. Albeit this is important and has to be done. But is this all that matters in your life? There is more to any person than this!!! unfortunately after the allocated support hours have been utilised delivering this support then completing the ridiculous paperwork that goes with it, the service user is almost every time sitting in a room/flat doing NOTHING ELSE. This makes me really sad and frustrated and if you could put yourself in that position I'm sure you would find your self-esteem and mental health would not be in a great place. (Worker)

Flailing in the face of belonging paradoxes was also characterized by discursive 'either/or' responses both amongst workers and their managers, reflecting disengagement in the form of a strong sense of distancing (cognitively and 
emotionally) from senior management decisions to invest in more commercial-oriented funding activities. In the reaction formation responses (Lewis 2000) below, cognitive and emotional attachment to the organization appears threatened due to a lack of belief in the shifting identity of the organization and talk of a broader unsupportive discursive context in which one set of (industry/commercial) values is deemed superior to its 'polar opposite'.

My perception is that HealthOrg is focussing all its attention on their profile, media work, fundraising \& campaigns and this sometimes feels that they are ignoring, forgetting about the services and the people we support on a daily basis (Worker).

There is a growing feeling that staff at service level are being treated with some contempt and are being dictated to by individuals who have come from industry backgrounds that are at the polar opposite of what social care is.....There is a sense of feeling that staff who work hard at service level are perceived as being at odds with where the organization is looking to go in future (Manager).

\section{'Muddling Through' Responses and Paradoxes of Performing}

Muddling through' responses to paradoxes of performing hint at the adoption of a both/and perspective (Lewis 2000), where participants avoid privileging one pole or another while engaging with their job roles, seeking to work through the tensions as best they can, through ongoing support and collaboration with their immediate line managers. In the text below a worker expresses the importance of maintaining mutually supportive relationships aimed at fulfilling responsibilities to others, suggestive of an ethic of care (Simola 2003).

As our service is going through a lot of changes it was important that the service users felt reassured and supported, myself and the manager had one to one meetings and reviews with every user to construct and adapt a timetable to make sure everyone's needs were met (Worker)

The following narrative, written by a senior manager, reflects a similar sentiment about the pivotal role of frontline managers in building a context of engagement, rooted in a sensitivity to the feelings and concerns of different stakeholders. Here, emphasis is placed on constructing shared meanings of events, and recognizing team members' commitments within a process of collaborative inquiry and problem solving.

Currently in our services we are experiencing problems around being able to maintain effective staffing levels against service delivery expectations.... This is an ongoing problem that is made difficult by external pressures. This has required the local management team to genuinely share thoughts and suggestions in a constructive way that enables rota problems to be met.... therefore good communication between the management team ensures we are looking to minimise problems around service delivery where we can. (Senior Manager)

In summary, these responses point to moments of engagement that are grounded in an ethic of care, characterized by dialogic practices which allow for the ongoing construction of meaning about paradoxical tensions at play; providing a dynamic conversational space for stepping back, discussing, reordering, and coming up with new solutions, and a caring space where people can voice difficulties, and absurdities, even those for which line managers cannot offer immediate or final solutions. However, there is also talk of increasing job strain being placed on line managers' consistent with the observed reduction in managerial 'presence' and a lack of relational reciprocity of the type illustrated above.

Although I have worked with my line managers in the past to find effective solutions to problems, I now find that HealthOrg is increasing the workload of their service managers to the extent that they now don't have the time to devote to closely managing a team. For example, it is now common for service managers to have to manage several teams at a time - leading to a deterioration in the quality of management, and ultimately in service provision (Manager).

Notably, we coded only one managerial response to 'muddling through' presented below, which highlights problems associated with fulfilling this 'conduit' role.

The increase in paperwork to evidence what we are doing is taking away from face to face contact with staff and service users, managers and staff. The systems and processes are cumbersome and whilst I appreciate the need to comply with our governance I feel the organization has become very corporate, there is less opportunity to be innovative or creative in services at a local level. I am unclear now as to the level of my authority to make decisions as most have to be run by ops manager or at a higher level. In this respect I can often feel like a conduit between the services and exec. (Manager)

\section{Generating Responses}

Our final category of responses-labelled 'generating', is characterized by the search for dynamic and caring 
conversational spaces where people have opportunities to engage in collaborative dialogue about what is happening and reflecting on why and how it occurs (Putnam et al. 2016) as suggested in the following response to a paradox of performing:

I have worked with my line manager to initiate a transformational change programme, we worked well together to initiate a business case and resources by taking lots of time to discuss options, tactics, potential risks or barriers, how others may feel about the change and I welcomed the opportunity to raise issues, concerns, challenges and opportunities (Manager).

While there is only one FTR coded to this category, generating responses are suggested in later development of workforce strategy documents and post-survey structural changes, spawned by a realization and acceptance amongst members of the senior team that paradoxical tensions are 'not going away' (HR business partner) and need to be managed on an ongoing basis. One intervention in response to performance paradoxes, includes the launch of a highly participative change programme that provides a more explicit role for workers as 'stakeholders' in strategic change, and involves a series of 'local roadshows' - where service managers and workers get together in teams to engage in collaborative inquiry, and work through ongoing performance tensions between care work and regulatory work. To date, this initiative has led to the generation of new procedures that are better aligned to different types of support packages (i.e. 2 or $24 \mathrm{~h}$ ), and the piloting of electronic tablets to facilitate ease of completing forms when workers are out in the field. These dialogic practices and ensuing adjusting responses (Smith and Lewis 2011) to paradoxes of engagement, points to a shifting mindset about change management at HealthOrg This eschews a conventional 'tell and sell' approach to change, in favour of one that builds dialogue at the heart of the change process. HR respondents talked about a growing recognition amongst members of the senior team that 'good conversation is key' in building engagement within a 'more with less climate', echoing observations by analysts elsewhere; of a growing 'popular awareness' amongst practitioners of constructionist models of change that are based on conversational techniques which allow for the emergence of multiple perspectives and new organizational realities (Bushe and Marshak 2009) This shift in thinking at HealthOrg is illustrated further in the following narrative, couched in an ethic of care:

We recognised that the underpinning values of HealthOrg were in danger of being lost in the drive for more efficiency, and a need to connect with staff in ways that enabled frank and open conversations for change, recognising the huge commitment of our people to the communities they serve. (HR Director)

In addition, emerging structural changes are beginning to address the belonging paradox evident in polarized views around business development and commercial work $\mathrm{v}$ care work. The management of these two activities has recently been combined into one role of 'Community Business Manager'. This is an inherently paradoxical label which draws on both VS (community) and NPM (business) discourse to portray and keep visible the simultaneous, persistent and opposing demands on HealthOrg staff, showing them as complementary and interwoven. This intervention may be indicative of a 'more-than' response to belonging and performing paradoxes that our study suggests are embedded in HealthOrg's strategic ambitions. A readiness for organizational members to discursively engage in this manner will be shaped by the effectiveness of current efforts to diffuse more collaborative and empowering management practices within HealthOrg.

\section{Discussion}

Our study was borne from an interest in the dynamics and context dependency of engagement in an era of increasing austerity and employer reliance on high levels of performance from workers and their managers. Rich examples are given of tensions of engagement emerging at the level of performing (competing tasks) and belonging (competing values, identities), linked to the wider economy and particular industry sector. The paradoxical nature of these tensions are shaped by the interplay of competing discourses, evident in managerial bulletins-exhorting managers and workers to do more with less, to raise service quality and cut costs including staffing levels-and in dialogue reported between workers and their senior /line managers-where responses coalesced around muddling through and flailing in the face of tensions.

Three key insights emerge from our study. First, our analysis explores discursively constructed 'moments' of performing work tasks that are infused with paradoxical tensions. We show how paradoxes of performance-engaging with what? and a paradox of belonging — engaging with whom? are discursively framed by the varying dominance of the two rival discourses of NPM and VS. This is evident across three kinds of responses labelled as: 'flailing', 'muddling through' and 'generating'. Each of the responses is embedded within an either/or, both/and, or 'more than' perspective about the competing elements at play (Putnam et al. 2016). We found no evidence of 'muddling through' with the belonging paradox, perhaps because this relates to 
engagement with the organization, and tensions arising from competing organizational values (according to our sample of respondents) were less open for discussion amidst talk of poor communications between workers and senior/head office personnel. This raises a red flag in terms of how the broader organizational context, including senior management communication and relating styles, can underpin, or undermine, an ethic of care while pursuing engagement in an era of austerity.

In contrast, it is at the task level that tensions stemming from paradoxes of performing appeared to be more openly discussed with line managers, enabling opportunities for joint problem solving and expressions of an ethic of care. Here, we note that the discursive interplay of opposites becomes a discursive resource that enables expression of an ethic of care; notably a source of dialogue for participants to build relationships in ways that enable them to 'muddle through' in their coping with paradoxes of performance. This is a potentially significant finding given earlier research into the role of line managers in fostering 'open and honest dialogue' within teams about increasingly demanding performance targets in contexts that require them to improve service quality and cut costs (Warhurst 2013, p. 50). Yet managers in our study seem to struggle in this 'conduit' role, similar to previous observations that 'employee voice' in the workplace is 'too challenging' for many managers (Purcell 2014), and that enabling conditions for people to 'speak up' within organizations remains elusive in the face of structural constraints (Morrison 2014) such as declining time for supervisors to discuss work problems and possible solutions with their subordinates.

Following from the above, our second key insight presents a more nuanced picture of the tension-reducing capacity of social relations and voice as expressed in Kahn's (1990) work, and recent research into the antecedents and processes of engagement (Rees et al. 2013). Both/and responses entail the opening of tensions to some form of dialogue, highlighting the function of the communicative context in shaping actors' perceptions of tensions as paradoxical and the adoption of active responses to these.

Third, and perhaps most strongly in terms of the data, our findings point to a range of ethical HRM issues associated with the organization and management of engagement-notably feelings of powerlessness expressed amongst some respondents, consistent with the notion of 'escalating citizenship' - where pressure to 'go the extra mile' becomes a normalized feature of working life (Bolino and Turnley 2003). Opportunities for staff to voice anxieties and stresses about such pressures, are linked with the availability of material and discursive resources, power to acquire these and to shape discourses regarding competing priorities, such as pursuing 'lower costs/higher service quality' (Reitz 2015).
Our findings suggest that for people to engage themselves in difficult situations, full of tensions, it is important that they can address them openly and together-a dynamic that is shaped by the ongoing discursive framing of organizational and individual work priorities, and the broader distribution of power between contradictory elements evident at different levels of decision-making (Hargrave and Van de Ven 2016, p. 3). At HealthOrg we observe the launch of new structures in support of collective inquiry and problem solving at organizational and departmental levels, alongside evidence of a declining space for dialogue between workers and managers in their every-day enactment of job roles, shaped by competing pressures and reduced time to coach and work with frontline service personnel.

\section{Limitations}

Generalizability is not the main purpose of our qualitative research, and we therefore issue caution about the potential 'transferability' of our findings to other situations (Stake 1995). Nevertheless, we have sought to provide sufficient contextual information for the reader to engage in "naturalistic generalization" in order to make judgements about whether or not findings can reasonably be generalized to their own specific field of practice (Robinson and Norris 2001, p. 306; Lincoln and Guba 1985). Stake argues that generalization of this kind involves the reader adding the present case to cases already known by her, thus providing a vicarious link with their own experience (Stake 1995, p. 85).

We also acknowledge the limitation of the cross-sectional nature of the data collected from frontline workers and managers at HealthOrg at one point in time. We cannot make inferences about how paradoxes of engagement might shape, and be shaped by, particular coping responses over time, such as 'muddling through'. Nevertheless, our data point to the importance of the communicative context in opening up or closing off worker participation in decision-making about working with tensions (depending on whether managers privilege monologue or dialogic modes of communication). Future research could usefully explore the possibilities offered by dialogic practices in the enablement of 'more than' or 'both/and' responses to engagement tensions in organizations like HealthOrg.

\section{Conclusion and Future Research}

Paradoxical engagement strategies cause tensions, and those targeted by these engagement strategies need to be supported and cared for. We have highlighted the ethical implications of workforce engagement strategies in an age of austerity, showing the importance of providing 
resources for dealing with tensions rooted in engagement when managers and workers face paradoxical demands. Our findings show that the act of being engaged in the context of HealthOrg is more a dynamic accomplishment rather than a static phenomenon, whereby workers and their managers cope with the tensions of paradoxical demands in terms of task performance and priorities (performing paradoxes) as well as tensions associated with being the kind of health worker that clients are perceived to need, who can spend time on tasks which enhance quality of life as well as basic requirements for compliance and housekeeping.

Tensions associated with values and identity reflect paradoxes of belonging and these seem to be associated with stress and dissatisfaction, which undermine engagement. Our findings are consistent with growing recognition of the need to treat engagement as more tension-filled, fragile, and thus less stable than psychologists have tended to suggest (Kahn and Heapy 2014). In the context of HealthOrg, an ethic of care towards managers and workers emerges as crucial to ensuring that tensions of engagement-marked by demands to engage in paradoxical tasks and involvement with clients-are accompanied by dialogue practices (embodied in performance reviews, team meetings etc) to find humane solutions for workers and managers as well as clients. Future research should address the enabling factors in the development of practices that create spaces for expressing doubt and talking about tensions and explore ways of managing the challenges of engagement where organization and management strategies produce paradoxical tensions.

While 'engagement as management practice' is a relatively nascent area of interest (Bailey et al. 2017, p. 35; Truss et al. 2013), our research can stimulate interest in sustainable and ethical workforce engagement strategies, to give more explicit consideration to the enhancement of dialogic practices based on an ethic of care: making explicit, the provision for such resources in order to better deal with paradoxes of engagement. For instance, McKie and colleagues provide a framework of 'organisation carescapes' offered as an aid in the analysis of employee policies, services and strategies in support of care within organizations grappling with workplace tensions (McKie et al. 2008, p. 21). Another fruitful line of inquiry is the exploration of how workforce engagement strategies both impact upon and are shaped by the interplay of broader paradox-discourses which set the conditions for how actors appropriate contradictions in organizational processes (Putnam et al. 2016, p. 77).

Future research should also address the ethics and power dynamics involved in engagement strategies than embed paradoxes, such as doing more with less; including the role of narrative practices and broader organizational discourses and social interactions in shaping this (Lawrence and Maitlis 2012; Leitch and Palmer 2010). Critical scrutiny could be given to the dominance of a unitary 'engagement narrative' that has come to colonize contemporary management discourse about how to motivate workers to 'go the extra mile' for themselves, their managers and their organizations (Keenoy 2014, p. 198) Additionally, further work could consider managerial experiences of their 'buffering' role (Mayo et al. 2012) in alleviating worker's stress-related responses to paradoxes of engagement, that is likely in turn, to shape perceptions of the paradox itself and responses to it.

Funding Helen Francis' Institution (Edinburgh Napier University) received funding from the case organization to conduct an employee survey for the case organization-this included three open questions used in the analysis of this paper.

\section{Compliance with Ethical Standards}

Conflict of interest Helen Francis and her co-author Anne Keegan have no conflict of interest or commercial relationship with the case organization, have not received any funding in their independent analysis of free text responses, or any further gathering and analysis of interview and documentary material used in this paper.

Open Access This article is distributed under the terms of the Creative Commons Attribution 4.0 International License (http://creativeco mmons.org/licenses/by/4.0/), which permits unrestricted use, distribution, and reproduction in any medium, provided you give appropriate credit to the original author(s) and the source, provide a link to the Creative Commons license, and indicate if changes were made.

\section{References}

Akin, G., \& Palmer, I. (2000). Putting metaphors to work for change in organizations. Organizational Dynamics, 28(3), 67-79.

Albrecht, S. L., Bakker, A. B., Gruman, Macey, H., \& Saks, A. M. (2015). Employee engagement, human resource management practices and competitive advantage, an integrated approach. Journal of Organizational Effectiveness, People and Performance, 2(1), 7-35.

Andriopoulos, C., \& Lewis, M. W. (2009). Exploitation-exploration tensions and organizational ambidexterity: Managing paradoxes of innovation. Organization Science, 20(4), 696-717.

Arrowsmith, J., \& Parker, J. (2013). The meaning of 'employee engagement' for the values and roles of the HRM function. The International Journal of Human Resource Management, 24(14), 2692-2712.

Aust, I., Brandl, J., \& Keegan, A. (2015). State-of-the-art and future directions for HRM from a paradox perspective: Introduction to the Special Issue. Zeitschrift fuer Personalforschung, 29(3), 194-213.

Bailey, C., Madden, A., Alfes, K., \& Fletcher, L. (2017). The meaning, antecedents and outcomes of employee engagement: A narrative synthesis. International Journal of Management Reviews, 19(1), 31-53.

Bakker, A. B., Albrecht, S. L., \& Leiter, M. P. (2011). Key questions regarding work engagement. European Journal of Work and Organizational Psychology, 20(1), 4-28.

Barge, J. K., \& Little, M. (2002). Dialogical wisdom, communicative practice, and organizational life. Communication Theory, 12(4), 375-397. 
Bauman, D. C. (2011). Evaluating ethical approaches to crisis leadership: Insights from unintentional harm research. Journal of Business Ethics, 98, 281-295.

Blismas, N. G., \& Dainty, A. R. (2003). Computer-aided qualitative data analysis: Panacea or paradox? Building Research \& Information, 31(6), 455-463.

Bolino, M. C., \& Turnley, W. H. (2003). Going the extra mile: Cultivating and managing employee citizenship behavior. The Academy of Management Executive, 17(3), 60-71.

Bushe, G. R., \& Marshak, R. J. (2009). Revisioning organization development, diagnostic and dialogic premises and patterns of practice. The Journal of Applied Behavioural Science, 45(3), 348-368.

Chaney, P., \& Wincott, D. (2014). Envisioning the third sector's welfare role: Critical discourse analysis of 'post-devolution' public policy in the UK, 1998-2012. Social Policy and Administration, 48(7), 757-781.

Crawford, E. R., Rich, B. L., Buckman, B., \& Bergeron, J. (2014). The antecedents and drivers of employee engagement. In C. Truss, R. Delbridge, K. Alfes, A. Shantz \& E. Soane (Eds.), Employee engagement in theory and practice (pp. 57-81). Routledge: Oxon.

Cunningham, I. (2010). Drawing from a bottomless well? Exploring the resilience of value-based psychological contracts in voluntary organizations. The International Journal of Human Resource Management, 21(5), 699-719.

Cunningham, I., \& Nickson, D. (2011). A gathering storm: Re-tendering and the voluntary sector workforce. International Journal of Public Sector Management, 24(7), 662-672.

Escobar, O. (2009). The dialogic turn: Dialogue for deliberation. In-Spire Journal of Law, Politics and Societies, 4(2), 42-70.

Fairclough, N. (2003). Analysing discourse, textual analysis for social research. Oxon: Routledge.

Fairclough, N. (2005). Peripheral vision. Discourse analysis in organization studies: The case for critical realism. Organization Studies, 26(6), 915-939.

Fletcher, L., \& Robinson, D. (2014). Measuring and understanding engagement. In C. Truss, R. Delbridge, K. Alfes, A. Shantz \& E. Soane (Eds.), Employee engagement in theory and practice (pp. 272-290). London: Routledge.

Francis, H., Parkes, C., \& Reddington, M. (2014). E-HR and international HRM: A critical perspective on the discursive framing of e-HR. The International Journal of Human Resource Management, 25(10), 1327-1350.

Freeney, Y., \& Fellenz, M. R. (2013). Work engagement, job design and the role of the social context at work: Exploring antecedents from a relational perspective. Human Relations, 66(11), $1427-1445$

Gilligan, C. (1995). Hearing the difference: Theorizing connection. Hypatia, 10(2), 120-127.

Goddard, J. (2014). The psychologisation of employment relations? Human Resource Management Journal, 24(1), 1-18.

Goffman, E. (1961). Encounters: Two studies in the sociology of interaction. Indianapolis: Bobbs-Merrill Co.

Grant, D., Hardy, C., Oswick, C., \& Putnam, L. (2004). Introduction-Organizational discourse: Exploring the field. In D. Grant, C. Hardy, C. Oswick \& L. Putnam (Eds.), The handbook of organizational discourse (pp. 1-36). London: Sage.

Greenwood, M. (2002). Ethics and HRM: A review and conceptual analysis. Journal of Business Ethics, 36(3), 261-278.

Greenwood, M. (2007). Stakeholder engagement: Beyond the myth of corporate responsibility. Journal of Business Ethics, 74(4), 315-327.

Greenwood, M., \& Freeman, R. E. (2011). Ethics and HRM: The contribution of stakeholder theory. Business and Professional Ethics Journal, 30, 269-292.
Groysberg, B., \& Slind, M. (2012). Talk Inc: How trusted leaders use conversation to power their organizations (pp. 776-783). Boston: Harvard Business Review Press.

Hargrave, T. J., \& Van de Ven, A. H. (2016). Integrating dialectical and paradox perspectives on managing contradictions in organizations. Organization Studies, 38(3-4), 319-339.

Harley, B. (2015). The one best way? 'Scientific' research on HRM and the threat to critical scholarship. Human Resource Management Journal, 25(4), 399-407.

Heracleous, L., \& Wirtz, J. (2014). Singapore airlines: Achieving sustainable advantage though mastering paradox. The Journal of Applied Behavioural Science, 50(2), 150-170.

Inkson, K. (2008). Are humans resources? Career Development International, 13(3), 270-279.

Isaacs, W. (1999). Dialogue and the art of thinking together. New York: Currency.

Jackson, K. M., \& Trochim, W. M. (2002). Concept mapping as an alternative approach for the analysis of open-ended survey responses. Organizational Research Methods, 5(4), 307-336.

Jacobs, G., \& Keegan, A. (2016). Ethical considerations and change recipients' reactions: 'It's not all about me'. Journal of Business Ethics. https://doi.org/10.1007/s10551-016-3311-7.

Janssens, M., \& Steyaert, C. (2009). HRM and performance: A plea for reflexivity in HRM studies. Journal of Management Studies, 46(1), 143-155.

Jarzabkowski, P., Lê, J. K., \& Van de Ven, A. H. (2013). Responding to competing strategic demands: How organizing, belonging, and performing paradoxes coevolve. Strategic Organization, 11, 245-280.

Jarzabkowski, P. A., \& Lê, J. K. (2017). We have to do this and that? You must be joking: Constructing and responding to paradox through humor. Organization Studies, 38(3-4), 433-462.

Jenkins, S., \& Delbridge, R. (2013). Context matters: examining 'soft' and 'hard' approaches to employee engagement in two workplaces. International Journal of Human Resource Management, 24(14), 2670-2691.

Kahn, W. (2010). The essence of engagement: Lessons from the field. In S. L. Albrecht (Ed.), Handbook of employee engagement. Perspectives, issues, research and practice (pp. 20-30). Cheltenham: Edward Elgar Publishing Limited.

Kahn, W. A. (1990). Psychological conditions of personal engagement and disengagement at work. Academy of Management Journal, $33(4), 692-724$.

Kahn, W. A. (1993). Caring for the caregivers: Patterns of organizational caregiving. Administrative Science Quarterly, 38(4), 539-564.

Kahn, W. A. (2005). Holding fast: The struggle to create resilient caregiving organizations. Hove: Brunner-Routledge.

Kahn, W. A., \& Heaphy, E. D. (2014). Relational contexts of personal engagement at work. In C. Truss, R. Delbridge, K. Alfes, A. Shantz \& E. Soane (Eds.), Employee engagement in theory and practice (pp. 82-96). Oxon: Routledge.

Keegan, A., Bitterling, I., Sylva, H., \& Hoeksema, L. (2017). Organizing the HRM function: Responses to paradoxes, variety, and dynamism. Human Resource Management. https://doi.org/10.1002/ hrm.21893.

Keegan, A., \& Francis, H. (2010). Practitioner talk: The changing textscape of HRM and emergence of HR business partnership. International Journal of Human Resource Management, 21(6), 873-898.

Keenoy, T. (2014). Engagement, a murmuration of objects? In C. Truss, R. Delbridge, K. Alfes, A. Shantz \& E. Soane (Eds.), Employee engagement in theory and practice (pp. 197-220). Oxon: Routledge. 
King, N. (2004). Using templates in the thematic analysis of text. In C. Cassell \& G. Symon (Eds.), Essential guide to qualitative methods in organizational research (pp. 256-270). London: Sage.

Lawrence, T. B., \& Maitlis, S. (2012). Care and possibility: Enacting an ethic of care through narrative practice. Academy of Management Review, 37(4), 641-663.

Legge, K. (1995). Human resource management: Rhetorics and realities. Basingstoke: Palgrave Macmillan.

Legge, K. (1999). Representing people at work. Organization, 6(2), 247-264.

Leitch, S., \& Palmer, I. (2010). Analysing texts in context: Current practices and new protocols for critical discourse analysis in organization studies. Journal of Management Studies, 47(6), 1194-1212.

Lewis, M. W. (2000). Exploring paradox: Toward a more comprehensive guide. Academy of Management Review, 25(4), 760-776.

Lewis, M. W., \& Smith, W. K. (2014). Paradox as a metatheoretical perspective: Sharpening the focus and widening the scope. The Journal of Applied Behavioral Science, 50(2), 127-149.

Liedtka, J. M. (1996). Feminist morality and competitive reality: A role for an ethic of care? Business Ethics Quarterly, 6, 179-200.

Lincoln, Y., \& Guba, E. (1985). Naturalistic inquiry. London: Sage.

Luscher, L., Lewis, M., \& Ingram, A. (2006). The social construction of organizational change paradoxes. Journal of Organizational Change Management, 19(4), 491-502.

Luscher, L., \& Lewis, M. W. (2008). Organizational change and managerial sensemaking: Working through paradox. Academy of Management Journal, 51, 221-240.

Machold, S., Ahmed, P. K., \& Farquhar, S. S. (2008). Corporate governance and ethics: A feminist perspective. Journal of Business Ethics, 81(3), 665-678.

Mayo, M., Sanchez, J. I., Pastor, J. C., \& Rodriquez, A. (2012). Supervisor and co-worker support: A source congruence approach to buffering role conflict and physical stressors. The International Journal of Human Resource Management, 23(18), 3872-3889.

McKie, L., Hearn, J., Bowlby, S., Smith, A., \& Hogg, G. (2008). Organisation carescapes: Researching organisations, work and care. Working Paper. Hanken Press, Hanken School of Economics. http://eprints.hud.ac.uk/id/eprint/4996/.

Morrison, E. W. (2014). Employee voice and silence. Annual Review of Organizational Psychology and Organizational Behavior., 1(1), 173-197.

Oswick, C., Putnam, L. L., \& Keenoy, T. (2004). Tropes, discourse and organizing. In D. Grant, C. Hardy, C. Oswick \& L. Putnam (Eds.), The handbook of organizational discourse (pp. 105-127). London: Sage.

Palmer, I., \& Dunford, R. (2002). Managing discursive tension: The co-existence of individualist and collaborative discourses in flight centre. Journal of Management Studies, 39(8), 046-069.

Parkes, C. (2012). The OD role of HRM in ethics, corporate social responsibility (CSR) and sustainability. In H. Francis, L. Holbeche \& R. Reddington (Eds.), People and organisational development: A new agenda for organisational effectiveness (pp. 286-311). London: Chartered Institute of Personnel and Development.

Parkes, C., \& Harris, M. (Eds.). (2008). Corporate responsibility, ethics and strategic HRM. In Strategic human resource management, building research-based practice (pp. 296-326). London: CIPD Publishing.

Potter, T., Brotherton, G., \& Hyland, C. (2012). The voluntary sector in transition: Changing priorities, changing ideologies. Birmingham: Newman University College and Centre for Voluntary actions.

Purcell, J. (2014). Provocation Series Paper: Disengaging from engagement. Human Resource Management Journal, 24(3), 241-254.
Putnam, L. L., Fairhurst, G. T., \& Banghart, S. G. (2016). Contradictions, dialectics, and paradoxes in organizations: A constitutive approach. Academy of Management Annals, 10(1), 65-171.

Rees, C., Alfes, K., \& Gatenby, M. (2013). Employee voice and engagement: Connections and consequences. The International Journal of Human Resource Management, 24(14), 2780-2798.

Rees, J. (2014). Public sector commissioning and the third sector: Old wine in new bottles? Public Policy and Administration, 29(1), 45-63.

Reitz, M. (2015). Dialogue in organizations: Developing relational leadership. London: Palgrave Macmillan.

Robertson, I. T., \& Cooper, C. L. (2010). Full engagement: The integration of employee engagement and psychological well-being. Leadership \& Organization Development Journal, 31(4), 324-336.

Robinson, J. E., \& Norris, N. F. (2001). Generalisation: The linchpin of evidence-based practice? Educational Action Research, 9(2), 303-310.

Saks, A. M. (2006). Antecedents and consequences of employee engagement. Journal of Managerial Psychology, 21(7), 600-619.

Schaufeli, W., \& Salanova, M. (2011). Work engagement: On how to better catch a slippery concept. European Journal of Work and Organizational Psychology, 20(1), 39-46.

Schaufeli, W. B. (2014). What is engagement? In C. Truss, R. Delbridge, K. Alfes, A. Shantz \& E. Soane (Eds.), Employee engagement in theory and practice (pp. 15-35). Oxon: Routledge.

Shuck, B. M., Rocco, T. S., \& Albornoz, C. A. (2011). Exploring employee engagement from the employee perspective: Implications for HRD. Journal of European Industrial Training, 35(4), $300-325$.

Simola, S. (2003). Ethics of justice and care in corporate crisis management. Journal of Business Ethics, 46, 351-361.

Smith, W. K., \& Lewis, M. (2011). Toward a theory of paradox: A dynamic equilibrium model of organizing. Academy of Management Review, 36(2), 381-403.

Spicer, A., Alvesson, M., \& Karreman, D. (2009). Critical performativity: The unfinished business of critical management studies. Human Relations, 62(4), 537-560.

Stake, R. E. (1995). The art of case study research. Thousand Oaks: Sage.

Stewart, J., \& Zediker, K. (2000). Dialogue as tensional, ethical practice. Southern Communication Journal, 65(2), 224-242.

Thompson, P. (2011). The trouble with HR. Human Resource Management Journal, 21 (4), 355-367

Truss, C., Shantz, A., Soane, E., Alfes, K., \& Delbridge, R. (2013). Employee engagement, organizational performance and individual well-being: Exploring the evidence, developing the theory. The International Journal of Human Resource Management, 24(14), 2657-2669.

Vaara, E., Sorsa, V., \& Pälli, P. (2010). On the force potential of strategy texts: A critical discourse analysis of a strategic plan and its power effects in a city organization. Organization, 17(6), 685-702.

Warhurst, R. P. (2013). Learning in an age of cuts: Managers as enablers of workplace learning. Journal of Workplace Learning, 25(1), 37-57.

Watson, T. (1994). In search of management. London: Routledge.

Watson, T. J. (2010). Critical social science, pragmatism and the realities of HRM. International Journal of Human Resource Management, 21(6), 915-928.

Wollard, K. K. (2011). Quiet desperation: Another perspective on employee engagement. Advances in Developing Human Resources, 13(4), 526-537. 